operate a strict non-prescribing policy. A significant proportion of our notifications were provided by "non-statutory" sources such as voluntary agencies and drug users themselves. Although multisource enumeration methods are expensive and timeconsuming, they demonstrate the independence of different sources of information. The value of individual sources for continued monitoring varies from place to place and from time to time, according to patterns of local service provision and the views of the users themselves about the value of the different agencies. Local knowledge is vital for making choices about which agencies reflect trends most accurately, and choices may need to be revised as patterns of service use change over time.

University Department of Psychiatry

\section{ROBERT PEVEler}

Warneford Hospital

Oxford

\section{Reference}

Peveler, R. C., Green, R. \& Mandelbrote, B. M. (1988) The prevalence of heroin misuse in Oxford City. British Journal of Addiction (in press).

\section{ECT in Parkinsonism with Affective Disorder}

SIR: The paper by Atre-Vaidya \& Jampala (Journal, January 1988, 152, 55-58) is a most interesting contribution to, but not a complete solution of, the problem of the effectiveness of ECT in these conditions. Sometimes parkinsonism responds; sometimes depression responds; sometimes both respond; sometimes neither responds.

I have made observations on five patients who were referred to me for ECT for severe depression, who also had independently-made diagnoses of Parkinson's disease, and who had not recently received levodopa or anti-psychotic drugs. As well as clinical observation, several rating scales were used, before treatment and after treatment. Memory was rated by the Mental Status Questionnaire (Kahn et $a l, 1960)$ and the forward digit span of the Wechsler memory sub-scale (Wechsler, 1965). Depression was rated on the Hamilton scale (Hamilton, 1960). Parkinsonism was rated on the Simpson Angus scale (Simpson \& Angus, 1970), and the Webster scale (Webster, 1968).

Treatments were right unilateral, with electroencephalographic recording of adequate seizure activity. In three cases parkinsonism and depression both improved. In one case parkinsonism was not usefully improved (although improved on rating scales), but depression improved. One patient, previously bedridden by parkinsonism, became mobile enough to walk to a window and try to jump out. Her depression was not improved usefully, even after nine treatments.

By the fourth treatment, the Simpson-Angus scores had improved in all cases. By the fifth treatment the Webster scale had improved in all cases. Memory worsened temporarily in one case, and improved in the others.

At follow-up, improvement in parkinsonism is maintained four years later in one patient; it relapsed in one month in one patient and at one to two months in two others. Follow-up is incomplete in one.

\section{Peter Birkett}

2 Copeland Drive

Suffern, New York 10901

USA

\section{References}

HamiLton, M. (1960) A rating scale for depression. Journal of Neurology. Neurosurgery, and Psychiatry, 23, 56-59.

Kahn, L. K., Goldfarb, A. J., Pollack, M. \& Peck, A. (1960) Brief objective measures for the determination of mental status in the aged. American Journal of Psychiatry, 117, 326-328.

SiMPSON, G. \& ANGUS, J. W. S. (1970) Drug induced extrapyramidal disorders. Acta Psychiatrica Scandinavica, Suppl. 212, 11-19.

WeBsTER, D. D. (1968) Critical analysis of the disability in Parkinson's disease. Modern Therapeutics, 5, 257-282.

WECHSLER, D. (1945) A standardized memory scale for clinical use. Journal of Psychology, 19, 87-95.

\section{Failure to Convulse with ECT}

SIR: Whatever the constitutional or other factors involved, failure to convulse with ECT, as described by Sharpe \& Andrew (Journal, January 1988, 152, 134-136), indicates an inadequate or inefficient type of stimulus for that patient.

Since the patient resistance is unknown, but probably between 200 and 500 ohms, the stimulus E2 with Ectron Duopulse IV on setting 2 would have given a dosage of between 215 and $416 \mathrm{mC}$; El on setting 1 of between 328 and $683 \mathrm{mC}$. In both cases the duration is $1.7 \mathrm{~s}$. The last $4 \mathrm{~ms}$ of each semi-sine wave is largely ineffective because of falling potential, so that the effective stimulus is 108-208 $\mathrm{mC}$ (E2), and 164-342 mC (El).

With stimulus $\mathrm{T}$ (Transpsycon on $50 \mathrm{~J}$ setting) the output is between 336 and $540 \mathrm{mC}$ in about $1.25 \mathrm{~s}$. Owing to the rapid exponential fall of potential with this capacitor discharge type of apparatus the effective stimulus is limited to the first $0.5-0.75 \mathrm{~s}$.

The optimum parameter levels for ECT are still uncertain, but the above durations are probably too short, and the effective current too low, to induce seizures in every patient.

It is impossible to allow for all the variables, but the use of a constant current stimulus largely compensates for variation in the patient resistance. Most 